\title{
PReS-FINAL-2104: Disease course and predictors of outcome in systemic onset juvenile idiopathic arthritis
}

\author{
S Soponkanaporn", S Vilaiyuk \\ From 20th Pediatric Rheumatology European Society (PReS) Congress \\ Ljubljana, Slovenia. 25-29 September 2013
}

\begin{abstract}
Introduction
Systemic juvenile idiopathic arthritis (SJIA) is the most common subtype of JIA in Thailand, which represents approximately 33 percents of all JIA patients. The disease course of SJIA and outcome of treatment were varied, depending on multi-factors. In the previous studies, persistent systemic features, younger age at onset, and arthritis of hip are predictors of poor functional outcome in SJIA. Since the development of biologic agents in this era improves the quality of life and outcome in SJIA patients, the disease course and predictors of outcome in SJIA have changed in the past 10 years.
\end{abstract}

\section{Objectives}

To evaluate disease status, functional outcome, structural damage, and prognostic factors of SJIA outcome.

\section{Methods}

Patients who were diagnosed with SJIA according to International League of Associations for Rheumatology (ILAR) criteria in Ramathibodi hospital between April 1997 and April 2013 were enrolled in this study and data records were reviewed. Disease status was evaluated by using European League Against Rheumatism (EULAR). Functional outcome was assessed by American College of Rheumatology core set criteria, including Child Health Assessment Questionnaire (CHAQ), physician global assessment, parent/patient global assessment, number of active joints, number of limited joints, and erythrocyte sedimentation rate (ESR), while radiographs were interpreted by radiologist using Dale radiographic classification system for structural damage evaluation. Prognostic factors of moderate to severe disability (defined using a CHAQ score 20.75 ) and moderate to severe radiographic damage (defined using Dale radiographic classification grading $\geq 3$ ) were analyzed by multivariable logistic regression models.

\section{Results}

Fifty-two patients (24 boys and 28 girls) were enrolled. The mean age of onset was 5.4 years old (6 months 14.1 years). The mean follow up period was 43.1 months (6.3-169.6 months). The most common presentations were fever (100\%), arthritis (100\%) and salmon rash (75\%). The patterns of arthritis were $55.8 \%$ polyarthritis and $44.2 \%$ oligoarthritis. The most commonly involved joints were the wrist $(69.2 \%)$ and knee $(67.3 \%)$. Treatment included systemic steroid (88.5\%), disease-modifying antirheumatic drugs (86.5\%), and biologic agents (42.3\%). Among patients taking biologic agents, five received etanercept, one received infliximab, and fifteen received tocilizumab. Nine patients achieved complete remission, one patient with clinical inactive, thirty-three patients had stable disease, and six patients still had active disease. Six patients (12\%) developed macrophage activation syndrome (MAS) during the disease course. Two patients died from MAS and severe infection, one patient died from severe infection. Seven patients (13.5\%) had moderate to severe disability. The predictor of a CHAQ score $\geq 0.75$ was initial presentation of polyarthritis ( $\mathrm{p}$ 0.012). Eleven patients (32.4\%) had moderate to severe radiographic damage and neutrophil counts at presentation $\geq 12000$ cells $/ \mathrm{mm}^{3}$ was the only significant predictor for structural damage (p 0.028). 


\section{Conclusion}

Polyarthritis at initial presentation may predict the development of a poor functional outcome. The prognostic factor of radiographic damage was neutrophilia. Infection is the major cause of death in SJIA.

\section{Disclosure of interest}

None declared.

Published: 5 December 2013

doi:10.1186/1546-0096-11-S2-P116

Cite this article as: Soponkanaporn and Vilaiyuk: PReS-FINAL-2104:

Disease course and predictors of outcome in systemic onset juvenile

idiopathic arthritis. Pediatric Rheumatology 2013 11(Suppl 2):P116.

Submit your next manuscript to BioMed Central and take full advantage of:

- Convenient online submission

- Thorough peer review

- No space constraints or color figure charges

- Immediate publication on acceptance

- Inclusion in PubMed, CAS, Scopus and Google Scholar

- Research which is freely available for redistribution

Submit your manuscript at www.biomedcentral.com/submit 